CARLOS PEREDA

\title{
Presencia de Ramón Xirau *
}

OCTAVIO PAZ, un vez más, ha definido exactamente aquello que procuraba definir: Ramón Xirau es un hombre-puente. Puente entre lenguas, tradiciones, disciplinas, pero también, puente entre una multitud de solitarios con diferentes y hasta opuestos intereses. Puente, pues, entre los cielos y la tierra, pero también, puente entre diferentes tierras. Y Xirau ha sido puente no sólo en su vasta obra escrita de filósofo, de ensayista y de poeta, sino también en esa otra, más íntima, que como amigo, profesor o editor ha llevado a cabo en más de veinte años. Sus muchos y devotos compañeros de camino, la nunca suficientemente elogiada revista Diálogos, en fin, sus clases y conferencias dan testimonio de esta voluntad de vínculo. Como no podía ser de otra manera, también este heterogéneo volumen de homenaje refleja esa voluntad. Pero ¿por qué "voluntad de vínculo"? Mi respuesta: todo exilado anda a la búsqueda de amarras, con hambre de presencia. Amarras, presencia: conceptos claves en Xirau.

Variados son los nombres ilustres que congrega este volumen: desde Jaime García Terrés hasta Marco Antonio Montes de Oca, desde Salvador Elizondo hasta José Emilio Pacheco... Entre tantas páginas llenas de admiración y cariño, no me resigno, sin embargo, a dejar de leer dos poemas que, aunque no hablan de modo anecdótico de Xirau, mágicamente lo aluden. Tengo, además, una buena excusa: la poesía, la propia y la ajena, ha sido la sustancia misma del pensamiento, de la vida de Xirau.

El primer poema es de Paz. Multiplicidad de materiales y perspectivas componen esa calle Galeana (la calle de San Angel donde Xirau ha vivido por mucho tiempo) que es todas las calles, que es todos los ruidos, que es todas las tardes, que es todos los incendios y

* Palabras pronunciadas en la presentación del libro Presencia de Ramón Xirau. Coordinación de Difusión Cultural, UNAM, México, 1986. 
todas las sombras, que es, tal vez, esa gran calle que es la vida misma. (La metáfora de la calle constituye, por supuesto, una de nustras versiones de la metáfora del río). Leo:

Por la calle de Galeana

Golpean martillos allá arriba voces pulverizadas

Desde la punta de la tarde bajan verticalmente los albañiles

Estamos entre azul y buenas noches aquí comienzan los baldios

Un charco anémico de pronto llamea la sombra de un colibrí lo incendia
Al llegar a las primeras casas el verano se oxida
Alguien ha cerrado la puerta alguien habla con su sombra
Pardea ya no hay nadie en la calle ni siquiera este perro asustado de andar solo por ella Da miedo cerrar los ojos

El segundo poema que quiero leer es de Ida Vitale y conforma variaciones, según Ida, empobrecidas del gran poema de Xirau Gradas. Vuelvo a leer no sólo sabiendo el lugar que ocupa la poesía en la vida de Xirau, sino sobre todo sabiendo el lugar que ocupa la lectura de poesía en su vida. (Excelente poeta, Xirau, para ocultárnoslo mejor sólo ha ejercido en catalán; en castellano lo conocemos ante todo como lector de poesía, como lector de Villaurrutia, de Gorostiza, de $\mathrm{Paz}$, de sor Juana...). Leo, entonces, acerca de esos titubeantes puentes que son las barcas, y la belleza:

Oh, barcas. Todo es ejercicio de belleza

Oh barcas. Todo es ejercicio de belleza y todo es mar, y el mar recala en todo, terso, templado.
Abra, cala, ruedo de ramblas, cuarzo donde el azul es más intenso y el oro cae en polvo y el leve viento no lo mueve. 
Blancas barcas se hamacan

flotan leves.

¿Sobre el pastizal baila su fiesta?

La madre mar quisiera parirnos y acunarnos.

El padre mar aletea como un gallo sagrado, levanta espumas, mitologías, letras,

golpea rocas, declina ante lo verde

que se atreve ante él

y retrocede y deja un signo más,

un escrúpulo último, un instante de arena.

Mar que nunca es un fin

sino un medio perpetuo

donde blancas barcas se hamacan,

letíficas

y todo es ejercicio de belleza.

Alguien tal vez se pregunte: pero c qué aguas, qué mares corren bajo tantos puentes, bajo tantas barcas? Me atrevería a responder: en Ramón Xirau se trata siempre de la misma agua, siempre de eso que, con una expresión teñida de nostalgias, todavía llamamos la "vida del espíritu”. 